\title{
Study of Magnesium Level as an Indicator of Diabetic Complications
}

\author{
Nawal SK ${ }^{1}$, Srivastava $C^{2}$ \\ ${ }^{1}$ Dr. Subodh Kumar Nawal, Associate Professor, Pulmonary Medicine, SGT Medical College \& Hospital, Budera, \\ Gurgaon, India, ${ }^{2}$ Dr Chandrashekhar Srivastava, Assistant Professor, Depatment of Medicine, Major S D Singh Medical college, \\ Fatehgarh,
}

Address for correspondence: Dr Chandrashekhar Shrivastava, Email: ccsrivastava9oct@ gmail.com

\begin{abstract}
Background: Type 2 diabetes has become a leading cause of morbidity and mortality world over. Magnesium depletion has a negative impact on glucose homeostasis and insulin sensitivity in patients with Type 2 diabetes. Magnesium deficiency can lead to development of complications such as retinopathy, nphropathy, thrombosis and hypertension. Material and Methods: The case control type of study was carried out on 50 age and sex matched healthy controls and 50 type 2 diabetic patients who attended the outpatient and inpatient department of medicine in tertiary care medical institute. All patients and controls underwent thorough clinical examination and estimation of serum magnesium, FBS, PPBS, lipid profile and urea, creatinine levels. Results: $46 \%$ of diabetic patients had low serum magnesium levels $(\mathrm{Mg} 2+$ level $<1.5 \mathrm{mg} / \mathrm{dL})$ and $6 \%$ of controls had low serum magnesium levels $(\mathrm{Mg} 2+$ level $<1.5 \mathrm{mg} / \mathrm{dL})$. The mean serum magnesium levels were $1.79 \pm 0.34 \mathrm{mg} / \mathrm{dL}$ and $2.12 \pm 0.29 \mathrm{mg} / \mathrm{dL}$, in diabetics and controls respectively ( $\mathrm{p}$ value $<0.0001$ highly significant). In this study hypomagnesaemia $(\mathrm{Mg} 2+$ level $<1.5 \mathrm{mg} / \mathrm{dl})$ was correlating with neuropathy and retinopathy, and the results were highly significant. Conclusion: This study demonstrated that Low Magnesium status is common in Type 2 diabetes mellitus patients when compared to non diabetic controls. It may be prudent in clinical practice to periodically monitor plasma magnesium concentration in diabetic patients. If plasma magnesium is low, an intervention to increase dietary intake of magnesium maybe beneficial.
\end{abstract}

Keywords: Diabetes Mellitus, Magnesium, Hypomagnesaemia, Neuropathy, Retinopathy.

\section{Introduction}

India leads in the world with its largest number of diabetes subjects as compared with any other given country It has been estimated that presently 19.4 million individuals are affected by diabetes and these numbers are expected to increase to 57.2 million by the year 2025 (1/6th of world total)[1]. Hypomagnesemia has long been associated with diabetes mellitus [2]. Serum magnesium levels are associated with diabetic control and complications. Low level of serum magnesium has been reported in children with insulin-dependent diabetes $[3,4]$.

Magnesium depletion has a negative impact on glucose homeostasis and insulin sensitivity in patients with Type 2 diabetes. Magnesium deficiency can lead to development of complications such as retinopathy, thrombosis, nephropathy and hypertension. Several

Manuscript received: $24^{\text {th }}$ June 2015

Reviewed: $17^{\text {th }}$ July 2015

Author Corrected: $19^{\text {th }}$ July 2015

Accepted for Publication: $2^{\text {nd }}$ Aug 2015 studies have shown that high prevalence of low serum magnesium concentrations in Type 2 diabetes when compared to healthy controls.

Magnesium deficiency may result in failure to inhibit entry of calcium into myocardial cells, failure to extrude calcium from the cells, formation of crystals in mitochondria and failure of sarcoplasmic reticulum to sequester excess calcium [5].

Resnick and associates suggest that extracellular and intracellular magnesium deficiency is typical in chronic, stable, mild type 2 diabetes and may be a strong predisposing factor for the development of the excess cardiovascular morbidity associated with diabetes. These investigators showed that the levels of serum ionized magnesium and erythrocyte intracellular free magnesium were significantly lower in 22 untreated patients with type 2 diabetes and mild hyperglycemia 
than they were in 30 healthy control subjects $(\mathrm{P}<.001)$. Serum total magnesium was not reduced [6].

It is observed that low serum magnesium concentration and poor magnesium status are common in Type 2 diabetes mellitus. Preventing hypomagnesaemia in diabetes by supplementing magnesium may be helpful in increasing insulin sensitivity and delaying the development of late diabetic complications.

Therefore, the aim of the study is to compare the serum magnesium concentrations in patients with Type 2 diabetes and non-diabetic controls to assess its impact on complications.

\section{Material and Methods}

The present study was a prospective case control study conducted in the Department of Medicine in tertiary hospital. Fifty diagnosed type 2 diabetes mellitus patients as cases and 50 healthy controls were studied.

Inclusion criteria- All cases of Type 2 diabetes mellitus patients and non diabetic controls aged between 40 to 80 years attending diabetic clinic, at Medical college and hospital.

\section{Exclusion creiteria-}

- Patients with renal failure.

- Patients who suffered acute myocardial infarction in last six months

- Patients on diuretics.

- Patients with history of alcohol abuse.

- Patients on magnesium supplements/magnesium containing antacids.

- Mal absorption.

- Chronic diarrhea

Method Of Collection Of Data: Detailed history and clinical examination and biochemical investigations done, Details regarding presenting complaints, Past history of any Other diseases, History of comorbid diseases like hypertension, Ischemic heart disease etc had been enquired.

Family history of Diabetes and Hypertension was taken and detailed general physical examination was conducted. Pulse, Blood Pressure, Respiratory Rate, Temperature, Height, Weight, BMI and detailed systemic examination was carried out in all patients and controls. Fundoscopic examination was done in all patients and controls. 12 lead ECG done in all patients.

Biochemical Tests Done Among Diabetic Patients:

a) FBS and PPBS.

b) Serum magnesium Levels.

c) $\mathrm{HbA1C}$.

d) Lipid profile.

e) Blood Urea and Serum Creatinine

Biochemical Tests Done Among Non Diabetic Controls:

FBS and PPBS

Serum magnesium levels

Blood Urea and Serum Creatinine

Method of Estimation of Serum Magnesium-

Principle of the test:

It is an enzymatic end point method. Principle of reaction is that, the Calmagite combines with the magnesium to form a red complex in alkaline solution which is measured at 520 run.

Reagent is in liquid form ready for use.

A magnesium standard is provided with the reagent.

Wave length : $520 \mathrm{~nm}$.

Temperature: $370 \mathrm{c}$

Cuvette: $10 \mathrm{~nm}$ path length

Incubation: 5 minutes

Standard: $2 \mathrm{mg} / \mathrm{dL}$

Kit used in this study was RAICHEM's Magnesium liquid reagent The normal serum magnesium level is ranging from $1.8 \mathrm{mg} / \mathrm{Dl}$ to $2.9 \mathrm{mg} / \mathrm{dL}$. Serurn magnesium levels $<1.5 \mathrm{mg} / \mathrm{dL}$ is considered as low magnesium level in this study.

Statistical Analysis: Statistical analysis was done by calculation of range, median, mean, standard deviation, percentage, odds ratio, chi square test and $\mathrm{p}$ value.

Statistical software: The statistical software SPSS 10.0 was used for the analysis of the data and Microsoft word and excel have been used to generate graphs, tables etc

\section{Results}


Table: 1 Demographic distribution of cases and control

\begin{tabular}{|l|l|l|l|l|}
\hline \multirow{2}{*}{ Age in years } & Cases & \multicolumn{2}{l|}{ Controls } \\
\cline { 2 - 5 } & Number & \% & Number & \% \\
\hline $41-50$ & 16 & 24 & 14 & 28 \\
\hline $51-60$ & 18 & 36 & 16 & 32 \\
\hline $61-70$ & 14 & 28 & 12 & 24 \\
\hline $71-80$ & 6 & 12 & 6 & 12 \\
\hline$>80$ & - & - & 2 & 4 \\
\hline TOTA & 50 & 100 & 50 & 100 \\
\hline Mean \pm SD & $56.16 \pm 11.35$ & $55.76 \pm 10.36$ & \\
\hline
\end{tabular}

In the present study, patients were selected from 40 years to 85 years of age, majority of patients being in 51-60 years age group (36\%). The average mean age for the studied cases was $56.16 \pm 11.35$ year \& mean age of controls was $55.76 \pm$ 10.36 years.

Table No. 2: Effect of DM on Serum magnesium

\begin{tabular}{|l|l|l|}
\hline Serum Magnesium & Cases & Controls \\
\hline Range(Min-Max) & $1.0-2.50$ & $1.4-2.50$ \\
\hline Mean \pm SD & $1.79 \pm 0.34$ & $2.12 \pm 0.29$ \\
\hline $95 \%$ CI & $1.40-1.96$ & $1.99-2.12$ \\
\hline Significance & $\mathrm{P}<0.001$ & \\
\hline
\end{tabular}

In the present study there were significant hypomagnesemia in cases than controls, The average mean for the studied cases was $1.79 \pm 0.34$ and controls was $2.12 \pm 0.29$. Results were significant with a $\mathrm{p}$ value of $\mathrm{P}<0.001$.

Table No. 3: Comparison of serum Magnesium levels between cases and controls

\begin{tabular}{|l|l|l|}
\hline $\begin{array}{l}\text { Serum magnesium }(\mathrm{mg} / \mathrm{dl}) \\
\text { Normal range }=1.5-2.3 \mathrm{mg} / \mathrm{dl}\end{array}$ & Cases $(\mathrm{n}=50)$ & Controls $(\mathrm{n}=50)$ \\
\hline$<1.5$ & $23(46 \%)$ & $3(6 \%)$ \\
\hline $1.5-2.3$ & $22(44 \%)$ & $45(90 \%)$ \\
\hline$>2.3$ & $5(10 \%)$ & $2(4 \%)$ \\
\hline
\end{tabular}

Table no. 3 shows that serum magnesium was significantly lower in cases than controls that is $46 \%$ of cases had hypomagnesemia while only $6 \%$ of controls had hypoglycemia. Result was significant with p value $<0.01$.

Table No. 4: serum magnesium levels in patients with diabetic neuropathy

\begin{tabular}{|l|l|l|}
\hline S.magnesium & Diabetic Neuropathy $(\mathrm{n}=25)$ & No Neuropathy $(\mathrm{n}=25)$ \\
\hline Mean \pm SD & $1.49 \pm 0.49$ & $1.52 \pm 0.49$ \\
\hline Significance & P value $<0.1$ & \\
\hline
\end{tabular}

Table no. 4 shows that the average mean of hypomagnesemia in diabetic neuropathy patient was $1.49 \pm 0.49$ and in patients without neuropathy was $1.52 \pm 0.49$. the result was found to be significant with $\mathrm{p}$ value $<0.1$.

Table No. 5: number of patients having hypomagnesaemia with or without retinopathy

\begin{tabular}{|l|l|l|}
\hline S.magnesium & Retinopathy & No Retinopathy \\
\hline Hypomagnesaemia & $14(46 \%)$ & $3(12 \%)$ \\
\hline Normomagnesemia & $10(28 \%)$ & $7(24 \%)$ \\
\hline
\end{tabular}


Table no. 5 shows that $46 \%$ of diabetic retinopathy patients had hypomagnesemia and $12 \%$ of patients without retinopathy had hypomagnesemia, the results were significant.

\section{Discussion}

Magnesium, the second most common intracellular cation, plays a fundamental role as a cofactor in various enzymatic reactions involving energy metabolism. It is also involved at multiple levels in insulin secretion, binding and activity. Cellular magnesium deficiency can alter the activity of membrane bound sodium potassium ATPase [7] which is involved in maintenance of gradients of sodium, potassium and in glucose transport. The almost universal involvement of magnesium in a wide variety of cellular processes critical to glucose metabolism, insulin action and cardiovascular functions has been well-appreciated. The incidence of subclinical magnesium deficiency is common in diabetes and cardiovascular disorders.

Our observations revealed a definite lowering of serum magnesium in diabetic patients, especially in patients who had complication. These observations correlate well with previous studies [8].

The magnesium ion has been shown to play an important role in the metabolism of carbohydrates by activating various enzyme systems and helping insulin for its action. In this study it was observed that the mean serum magnesium level was statistically significantly low $(\mathrm{P}<0.001)$ in Diabetic patients without and with complications when compared with controls. This indicates the association of hypomagnesaemia with diabetes mellitus. These results are in accordance with the observation of Tosiello L [9], Kao WH [10], and Chamber E C [11]. In our study, serum magnesium level in cases with diabetic complications $(1.49 \pm 0.49)$ was much lower than those without complications $(1.52 \pm 0.49)$.

We also noted that in subjects with diabetic complications serum magnesium levels were much lower when compared to diabetics without complications. Hatwal A et al, Andrea Corsenello et al and Rodriguez Moran $\mathrm{M}$ et al have found similar results in patients with diabetic complications. Ishrath Kareem et al found that serum magnesium levels in patients with diabetic retinopathy were significantly lowered compared to patients without retinopathy [12]. Aradhana Sharma et al also found that serum magnesium levels were significantly lowered in patients with diabetic complications when compared to diabetic patients without complications [13].

Magnesium deficiency has been reported in theprevious studies in patients with type 2diabetes.However, some workers have also reported normal andeven high levels [14]. In the present study, serummagnesium concentrations of $23 \%$ patients with type 2diabetes were below the reference range. This confirmsto the reported prevalence of low plasma magnesiumstatus in type 2 diabetics in several studies, which ranged from 20- $39 \%$.The reasons for the high prevalence of magnesiumdeficiency in diabetes are not clear, but may includeincreased urinary loss, lower dietary intake, or impairedabsorption of magnesium compared to healthyindividuals Several studies have reported increasedurinarymagnesium excretion in type 2 diabetes [15]. Aspecific tubular defect in magnesium reabsorption inthick ascending loop of Henle is postulated [16].

In a study Alzaidaet al. [17] have found thatcellular uptake of magnesium is normally stimulated byinsulin. So insulin treatment may enhance cellularmagnesium uptake and result in increased prevalence ofhypomagnesemia. Serum levels of magnesium havebeen found by several investigators to correlateinversely with fasting blood glucoseconcentration and the percentage of $\mathrm{HbAlC}$. The present study revealedthat a higher prevalence of hypomagnesemia was foundin patients having $\mathrm{HbAlC}>$ $7 \%$ and $\mathrm{FBS}>130 \mathrm{mg} / \mathrm{dl}$.

Dr Mirza Sharifet al [18] study showed significant low values of serum magnesium $(\mathrm{P}<0.001)$ in patients of DM without complications when compared with controls. Further significant low values of serum mg $(\mathrm{P}<0.001)$ were found in patients of DM (Table $1 \&$ Fig 1) with complications when compared with control, similar to our study.

Another study done by Khubchandani et al [19] results also indicate that the patients with diabetic complications have significant rise in serum cholesterol and triglycerides. Probably hypomagnesemiaand increased serum cholesterol and triglyceride levels are responsible for micro- and macrovascular complications in diabetes. Thus, the purpose of this study was to 
gather information about the degree of control of diabetes and magnesium status.

Similarly,A cross sectional study on serum magnesium in diabetic patient done by Antin et al[20] found that significant co-relations between hypomagnesium and diabetic retinopathy (chisquare $=9.672, \mathrm{P}=0.0019$, $\mathrm{DF}=1$ )prevalence of hypomagnesemia in diabetic with complications was significantly higher compared to diabetic with no complications(47.36\%vs18.60\%)(chisquare=7.69, $\mathrm{P}=0.005 \mathrm{DF}=1)$. Higher prevalence of HbA1C $>7 \%$ (40.30\%vs $24.25 \%$ )but the result were not statistically significant for $\mathrm{P}$ value $<0.05$.Prevalence of hypomagnesemia in type 2 diabetic was $35 \%$.

Prevalence of hypomagnesemia was significantly higher in diabetic with microvascular complications compared to diabetic $s$ with no microvascular complications. Prevalence of hypomagnesium was significantly higher in patients withretinopathy .Prevalence of hypomagnesemia was higher in patients with FBS>130 and HbA1C >7 .No significantassociations existed between serum magnesium concentrations and other factors like age, sex, durations of diabetes, mode of treatment, diabetic neuropathy, ischemic heart disease and hypertension.

Kulkarni et al[21] studied in randomly chosen 100 Type 2 diabetic patients, and 100 non diabetic age / sex matched controls age group 30 to 70 years attending diabetic clinic and fount that $37 \%$ of diabetic patients had low serum magnesium levels $(\mathrm{Mg} 2+$ level $<1.5 \mathrm{mg} / \mathrm{dL})$ and $9 \%$ of controls had low serum magnesium levels $(\mathrm{Mg} 2+$ level $<1.5 \mathrm{mg} / \mathrm{dL})$. The mean serum magnesium levels were $1.96=0.54 \mathrm{mg} / \mathrm{dL}$ and $2.375+0.449 \mathrm{mg} / \mathrm{dL}$, in diabetics and controls respectively ( $\mathrm{p}$ value $<0.0001$ Highly significant). There is negative co relationship between Sr.Mg Levels and hypertension and there was also found to be negative correlation between $\mathrm{Mg}$ and retinopathy.

A Study of Serum Magnesium Levels in Diabetic Retinopathy Patients done by Dr kiran chahuan, The cross - sectional observational study was done with aimed whether there is any correlation between serum magnesium concentration and diabetic retinopathy in a rural population. They concluded that low serum magnesium levels are present in Type II diabetes mellitus in general and especially more significantly so in diabetes with retinopathy, in comparison to normal healthy control subjects.[22] similar to our finding of hypomagnesemia and diabetic retinopathy.
A metaanalysis of prospective cohort study for association between magnesium intake and risk of type 2 diabetesconcluded thatprovides further evidence supporting that magnesium intake is significantly inversely associated with risk of type 2 diabetes in a dose-response manner [23].

Another studies of Serum magnesium levels in patients with diabetic retinopathy found that Hypomagnesemia and albuminuria individually or in conjunction serve as indicators for dysglycemia and could be used as marker for the risk of development of diabetic retinopathy[24] .Sharma A et al [25] reported strong associationbetween hypomagnesaemia and retinopathy $(1.76 \pm 0.26 \mathrm{meq} / \mathrm{l}$, p < 0.005).As well as deValk HW et al [26] reported progression of diabetic retinopathy was related to plasma magnesium concentration ( $\mathrm{p}<0.05)$, and association between serum magnesium concentration and progression of retinopathy remained even after confounding HbA1c levels and duration of diseases ( $\mathrm{p}<$ 0.03). But in our present study we found strong correlation between duration of disease and low serum magnesium levels.

\section{Conclusion}

There is definite association between hypomagnesemia and diabetis mellitus Type II as well as its complication like Diabetic retionopathy and Neuropathy in our study.

The exact cause of diabetic hypomagnesaemia is still unknown but an increased urinary loss of magnesium may contribute to it. Hypomagnesaemia has been reported to occur at an increased frequency among patients with type 2 diabetes compared with their counter parts without diabetes, as suggested by many studies. Thus we conclude that the estimation of serum magnesium levels is helpful to monitor the severity of complications in type 2 diabetes and also be useful for proper medical intervention. Hence further studies on serum magnesium levels and on oral supplementation to prevent late complications of diabetes will be interesting and helpful.

\section{Funding: Nil}

Conflict of interest: Nil

Permission from IRB: Yes

\section{References}

1. King H, Aubert RE, Herman WH. Global burden of diabetes, 1995-2025: prevalence, numerical estimates, 
and projections. Diabetes Care. 1998 Sep;21(9):141431.

2. Mather HM, Nisbet JA, Burton GH, Poston GJ, BlandJM, Bailey PA, et al. Hypomagnesaemia in diabetes. Clin Chem Acta 1979;95(2):235-42.

3. Fort P, Lifshitz F. Magnesium status in children withinsulin-dependent diabetes mellitus. J Am Coll Nutr 1986;5(1):69-78.

4. Ewald U, Gebre-Medhin M, Turemo $\mathrm{T}$. Hypomagnesemiain diabetic children. Acta Paediatr Scand 1983;72(3): 367-71.

5. Bursch GE, Gibbs TD. Importance of magnesium deficiency in cardiovascular disease. Am Heart J. 1977 Nov;94(5):649-57.

6. Resnick LM, Altura BT, Gupta RK, Larsh JH , Alderman $\mathrm{MH}$, Altura BM. Intracellular and extracellular magnesium depletion in type 2 diabetes mellitus. Diabetologia. 1993 Aug;36(8):767-70.

7. Peterson CM, Jones RL. Minor hemoglobin, diabetic"control" and diseases of postsynthetic modification. Ann Intern Med 1977;87(4):489-91.

8. Ishrat K, Jaweed S, Bardapurkar J, Patil V. Study of $\mathrm{Mg}$, glycosylated $\mathrm{Hb}$ and lipid profile in diabetic retinopathy. Indian J Clin Bio 2004;19(2)124-7.

9. Tosiello L. Hypomagnesaemia and diabetes mellitus. A review of clinical implications. Arch Intern Med 1996; 156(1):1143 - 1148 .

10. Kao W H. Serum and dietary magnesium and the risk for type 2 diabetes mellitus. The Atherosclerosis risk in communities study. Arch Intern Med 1999; 159(8):2151 - 2159 .

11. Chambers EC, Heshkas, Gallagherd.Serum magnesium and type 2 diabetes in African Americans and Hispanics a Newyork Cohort. J Am Coll Nutr. 2006; 25:509 - 513 .

12. Ishrat Kareem, Jaweed SA. Bardapurkar JS et al. Study of magnesium, glycosylated hemoglobin and lipid profile in diabetic retinopathy. Indian Journal of Clinical Biochemistry, 2004; 19(2);124-127.
13. Sharma A, Dabla S, Agrawal RP, Barjatya H, Kochar DK, Kothari RP. Serum magnesium; An early predictor of course and complications of diabetes mellitus. J Indian Med Assoc. 2007 Jan;105(1):16, 18, 20 .

14. Hans CP, Sialy R,BansalDD; Magnesiumdeficiency and diabetes mellitus. Current Science, 2002; 83(12): 1456-1463.

15. Nadler JC, Rude RK. Disorders of magnesium metabolism. Endocrinol Metab Clin North Am. 1995 Sep;24(3):623-41.

16. Cole DEC, Quamme GA; Inherited Disorders of Renal Magnesium Handling. Journal of American Society of Nephrology, 2000;11(10): 1937-1947.

17. Alzaid AA, Dinneen SF, Moyer TP, Rizza RA. Effects of insulin on plasma magnesium in non-insulin dependent diabetes mellitus:evidence for insulin resistance. J Clin Endocrinol Metab. 1995 Apr;80(4):1376-81.

18. Dr Mirza Sharif Ahmed Baig, Dr Mohd Shamshuddin et al serum magnesium as a marker of diabetic complications Journal of Evolution of Medical and Dental Sciences/ Volume 1/ Issue 3/ July-Sept 2012;119-123.

19. Asha S Khubchandani, Hiren Sanghani. Study of Serum Magnesium and HbA1C in Diabetic Patients along with Changes in their Lipid Profiles. Indian Journal of Clinical Practice, 2013;23(11):717-719.

20. Dr.S.S.Antin, Dr. Mohan Kashinkunti. A Cross Sectional Study of Fasting Serum Magnesium Levels in the Patients with Type 2 Diabetes Mellitus and Its Relation to Diabetic Complications. Scholars Journal of Applied Medical Sciences (SJAMS) ISSN 2320-6691 (Online)Sch. J. App. Med. Sci., 2014; 2(2A):502-506.

21.A.G. Kulkarni1, Sachin K. ShendgeStudy of Serum Magnesium Levels in Types 2 Diabetes MellitusIOSR Journal of Dental and Medical Sciences (IOSR-JDMS) e-ISSN: 2279-0853, p-ISSN: 2279-0861.Volume 13, Issue 4 Ver. VII. (Apr. 2014), PP 115-119.

22. Dr. Kiran P. Chauhan Dr. N. HaridasA Study of Serum Magnesium Levels in Diabetic Retinopathy Patients. Indian Journal of Applied Research. 2013;3(5):482-484. 
23. Dong JY1, Xun P, He K, Qin LQ Magnesium intake and risk of type 2 diabetes: meta-analysis of prospective cohort studies. Diabetes Care. 2011 Sep;34(9):2116-22. doi: $10.2337 / \mathrm{dc} 11-0518$.

24. Dipankar Kundu, Manish Osta Serum magnesium levels in patients with diabetic retinopathy $\mathrm{J}$ Nat Sci Biol Med. 2013 Jan-Jun; 4(1): 113-116. doi: 10.4103/0976-9668.107270.
25. Sharma A, Dabla S, Agrawal RP, Barjatya H, Kochar DK, Kothari, RP (2007). Serum magnesium: an early predictor of course and complications of diabetes mellitus. Journal of Indian Med Assoc.105 (1); 16 -20.

26. de Valk HW, Hardus PL, van Rijn HJ, Erkelens DW. Plasma Magnesium concentration and progression of retinopathy. Diabetes Care. 1999 May;22(5):864-5.

\section{How to cite this article?}

Nawal SK, Srivastava C. Study of Magnesium Level as an Indicator of Diabetic Complications. Int J Med Res Rev 2015;3(7):726-732. doi: 10.17511/ijmrr.2015.i7.137. 